\title{
Percutaneous Anthropometry of Hand Dimensions for Stature Reconstruction Among Nigerians
}

\author{
Ibeabuchi Nwachukwu Mike ${ }^{1}$, Nandi Michael Ebe ${ }^{1,2 *}$, Olabiyi Olaleye Andrew ${ }^{1}$ and Okubike Emeka Ambrose ${ }^{1}$ \\ ${ }^{1}$ Department of Anatomy, University of Lagos, Nigeria \\ ${ }^{2}$ Department of Human Anatomy, Cross River University of Technology (CRUTECH), Nigeria \\ *Corresponding author: Nandi Michael Ebe, Department of Human Anatomy, Faculty of Basic Medical Sciences, Cross River University of Technology \\ (CRUTECH), Okuku-Campus, Cross River State, Nigeria
}

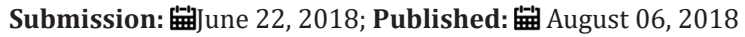

\begin{abstract}
Background: prediction of stature from skeletal remains or fragmented body parts is a challenging task since many times even the remains are not found in preserved form. Whereas, it is known that same regression formula for prediction of stature is not useable for all the population since anthropometric variations for different populations and even for geographical regions exist.
\end{abstract}

Objective: This study was designed to evaluate the association between hand dimensions with stature of Nigerian adults in University of Lagos.

Materials and Methods: This study involves Nigerian Medical students from University of Lagos, between the ages of 18 through $36 y e a r s . ~ A$ sample size of 230 participants including 100 males and 130 females were recruited for anthropometric exercise. Three variables were measured (Stretch Stature, Hand length and Hand breadth) following standard tools and procedures. Statistical analysis was done using Statistical Package for Social Sciences (SPSS) software version 20 Chicago Inc and Microsoft Excel, to present the various dataset in tables, graphs and linear scattered plots.

Results: The results recorded mean stature of $176.36 \pm 8.13 \mathrm{~cm}$ in the males and $164.38 \pm 6.62 \mathrm{~cm}$ in the females. Pearson moment correlation coefficient showed varying level of association between stature and hand dimensions with stronger correlation recorded between stature and hand length while hand breadth and stature showed a weak association. The data from this study will find immense relevance to an anatomist and forensic anthropologist when confronted with cases of missing identities in the crime scene.

Keywords: Forensic Sciences; Percutaneous Hand Anthropometry; Stature Reconstruction; Nigerians

\section{Introduction}

During forensic investigation of disaster incidences, the primary objective of any forensic scientist is the identification of the victims by analyzing the disintegrated human body parts. Therefore, reconstruction of stature from body segments can play a cardinal role since it has been shown by several authors as one of the bio-markers used in recovering human identity and profile the biological attributes of those involved [1-5]. Hand anthropometry is found to yield important predictive information about a person's stature and may further help in narrowing down the possible matching identities [6]. Stature gives an insight into various characteristics of a population including nutrition, health and genetics [7]. Stature is considered a vital parameter for human identification and one of the 'big fours' (Age, Sex, Stature and ethnicity or race) of forensic anthropology [8]. The stature of a person is an inherent feature that can play an important role in assessing the identity of dismembered human remains in crime scene. It has been one of the commonly used human attribute in describing the identity of an individual from time immemorial even before the introduction of forensic science [9-10].
These body segments can enable forensic expert to narrow down the stature from different parts of the body. With the rate of catastrophic disasters like earthquakes, plane crashes, fatal accident, cyclones etc., getting heightened every day, it has become imperative for such studies to be done to unravel the identify of deceased bodies in fragmentary and dismembered state. In conditions like this, a measurement of hand dimensions and becomes imperative to provide good approximation about the stature of a person towards personal identification [11-12]. Even though different authors have formulated different regression models from different parts of the body like trunk, head, upper and lower extremities and even hand and footprints [13-19]. There is still paucity of data among Nigerian adult population. Also, because every population has peculiar, more so, no research has predicted stature from hand dimensions among young adult Nigerian medical students in university of Lagos which is composite of major ethnic groups in Nigeria. Hence, the purpose of this study was to design peculiar and population-based regression models from percutaneous hand dimensions to reconstruct stature, thereby bridging the knowledge gap and vacuum that exists among Nigerians of the age group. 


\section{Methodology}

\section{Study design}

Subjects were informed of the objectives of the study, Stature, hand anthropometric dimensions, clothing requirements, measurement procedures and freedom to withdraw were let known to the participants who met inclusion and exclusion criteria. A sample size of 230 convenient sample participants (100 males and 130 females) who were all Nigerian medical students (undergraduates and postgraduates), ages between 18 through 36 years were invited to the department of Anatomy, College of medicine, University of Lagos for measurement.

\section{Percutaneous anthropometry}

\section{Stature measurement}

The measurement was taken as the maximum vertical distance from the floor to the vertex of the head using Stadiometer for the measurement. Protocol: Each participant was asked to stand bare- footed on the flat platform, maintaining an erect position with their heels, buttocks, upper back with the head in contact with the wall. The arms were placed on the sides of the thigh and instructed to inhale and hold their breath. Their heads were held in the Frankfort horizontal plane. This position is achieved when the line joining the orbitale to the tragion is horizontal or at right angles to the long axis of the body. The horizontal sliding bar is then positioned on the contact point of the vertex of the head and stature is recorded in centimeters.

\section{Hand length measurement}

Hand Length was measured as the distance from the marked mid-stylion (at the distal wrist crease) to the dactylion (Midstylion - dactylion) with the use of a sliding caliper.

Protocol: The subjects extended the right hand supinate, fully extending the fingers. The end pointer is placed on the marked midstylion line, the housing pointer applied to the dactylion (Figure 1).

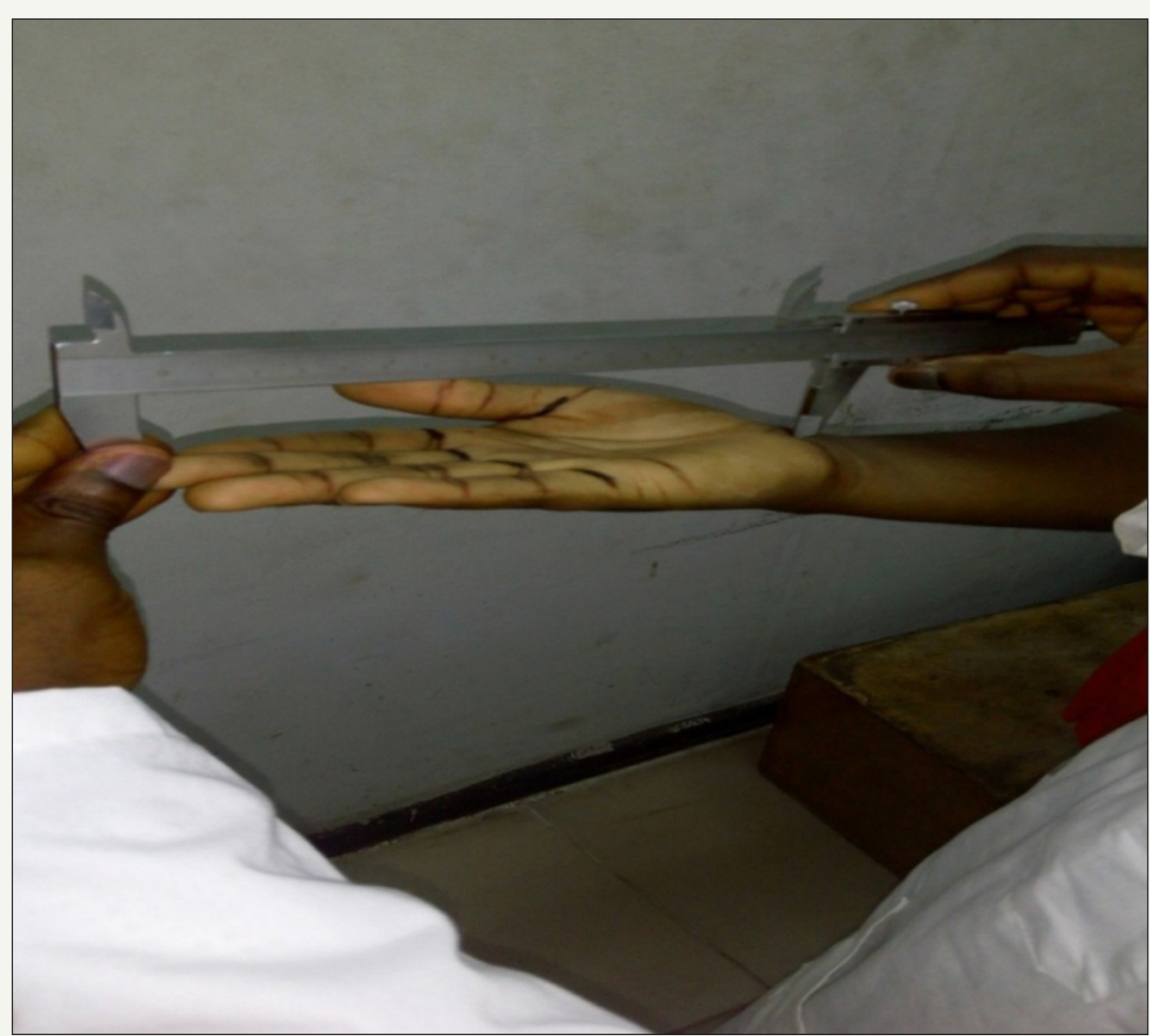

Figure 1: Measurement of the direct hand length using a sliding caliper.

\section{Hand breadth (HB)}

Hand breadth was measured as the distance between the metacarpale laterale and metacarpale mediale (bi-metacarpale).

Protocol: When the subject places the palm of the hand with fingers together firmly on a table. The investigator holds the small bone, caliper pointed downwards at a 45degree angle and palpates the landmarks with the third fingers, then applies the faces of the caliper with little pressure, but not to the extent of compressing the width, then measurement was to the nearest centimeters using the sliding caliper (Figure 2). 


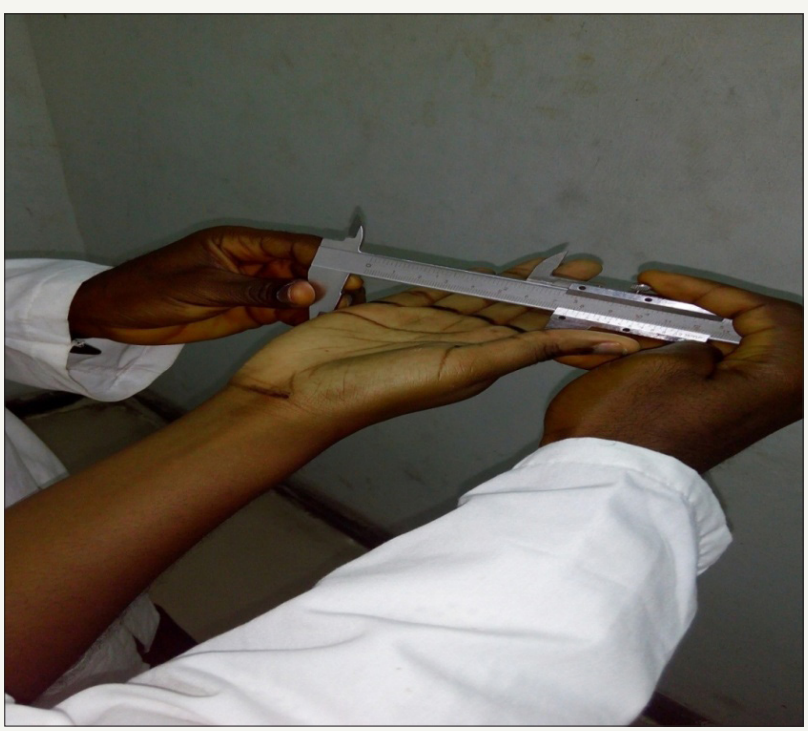

Figure 2: Measurement of the direct hand breadth.

The Chicago version 20 SPSS package was employed to analyze descriptive statistics, independent sample test for comparison of gender differences, paired t-test for analysis of bilateral asymmetry engaged, Pearson moment correlation was done to know the relationship between hand parameters and stature, simple and multiple linear regressions equation were derived using scatter plots and stepwise analysis, for prediction of stature from hand dimensions.

\section{Ethical approval}

The approval needed for researches involving Human and animal's models was obtained from the Health Research and Ethics Committee (HREC) of the College of Medicine, University of Lagos, Nigeria. A memo: CM/HREC/12/16/083 was provided to the lead researcher granting full approval for the commencement of this work.

\section{Subjects informed consent}

Oral and a signed written consent were obtained from each participant before measurements were taken and recorded in the study proforma.

\section{Results}

The results of this study are presented in tables and scattered linear graphs to show descriptive statistics (Table 1), Pearson moment correlation coefficient (Table 2); and formulated Durbin Watson single and stepwise regression equations and linear graphs (Figure 3-6). Table 1-presents the result of descriptive statistics of stretch stature, age, hand length and breadth in males and females of the study population. It was observed that Nigerian adults' males had higher values in all the study parameters than their female counterparts with significant difference when tested statistically $(\mathrm{P}<0.01)$.

Table1: Summary of descriptive statistics of direct hand dimensions $(\mathrm{cm})$ in the male and female sample.

\begin{tabular}{|c|c|c|c|c|c|c|c|}
\hline \multirow{2}{*}{ Hand Dimensions (cm) } & \multicolumn{2}{|c|}{ Males } & \multicolumn{2}{c|}{ Females } & \multirow{2}{*}{$\begin{array}{c}\text { Sig. (two- } \\
\text { tailed) }\end{array}$} \\
\cline { 2 - 7 } & Mean \pm SD & Range & Mean \pm SD & Range & & Mean \pm SD Diff \\
\hline SS (cm) & $76.36 \pm 8.13^{* *}$ & $158.5-191.2$ & $164.38 \pm 6.62^{* *}$ & $148-178.70$ & 36.34 & $8.86 \pm 4.3$ & 0.00 \\
\hline AGES (Years) & $20.26 \pm 3.21$ & $17-36$ & $19.58 \pm 2.75$ & $17-34$ & 12.38 & $2.10 \pm 0.10$ & 0.08 \\
\hline LHL (cm) & $19.86 \pm 1.12^{\text {dd }}$ & $17.00-22.5$ & $17.97 \pm 1.04^{\text {dd }}$ & $15.40-20.50$ & 13.39 & $1.92 \pm 0.14$ & 0.00 \\
\hline RHL (cm) & $20.13 \pm 1.11^{\text {dd }}$ & $17.00-22.5$ & $18.21 \pm 1.06^{\text {dd }}$ & $15.90-20.60$ & 13.36 & $1.88 \pm 0.16$ & 0.00 \\
\hline LHB (cm) & $8.42 \pm 0.48^{\text {dd }}$ & $7.40-7.50$ & $7.41 \pm 0.40^{\text {dd }}$ & $6.40-8.60$ & 16.44 & $0.98 \pm 0.06$ & 0.00 \\
\hline RHB (cm) & $8.53 \pm 0.49^{\text {dd }}$ & $7.40-9.50$ & $7.55 \pm 0.41^{\text {dd }}$ & $6.40-8.60$ & 16.02 & $0.96 \pm 0.08$ & 0.00 \\
\hline
\end{tabular}

values with similar superscript are significant different at $(\mathrm{p}<0.01)$ between male and female in left and right hand.

\section{Key}

SS: Stretch Stature; RHL: Right hand length; LHL: Left Hand Length; RHB: Right hand breadth; LHB: Left Hand Breadth; SD: Standard Deviation 
Table 2: Correlation coefficient (r) between stretch stature and direct hand measurement in the male and female sample.

\begin{tabular}{|c|c|c|}
\hline \multirow{2}{*}{ Hand Parameters (cm) } & Males Sample & Females Sample \\
\cline { 2 - 3 } & Pearson Correlation (r) & $0.71^{\text {aa }}$ \\
\hline Right Hand Length (RHL) & $0.75^{\text {aa }}$ & $0.71^{\text {aa }}$ \\
\hline Length Hand Length (LHL) & $0.74^{\text {aa }}$ & $0.51^{\text {aa }}$ \\
\hline Right Hand Breadth (RHB) & $0.31^{\text {aa }}$ & $0.50^{\text {aa }}$ \\
\hline Left Hand Breadth (LHB) & $0.40^{\text {aa }}$ & \\
\hline
\end{tabular}

Values with similar superscript aa Correlation significant at $\mathrm{P}<0.01$.

\section{Key}

SS: Stretch stature; RHL: Right hand length; LHL: Left Hand Length; RHB: Right hand breadth; LHB: Left Hand Breadth; r: Pearson Moment correlation coefficient

(Table 2) depicts data of the Pearson moments correlation coefficients between stature and the hand dimensions. It was noticed that hand length showed a stronger relationship with stature compare to the weaker values gotten from the hand breadth for both sexes. The results of the formulated regression equations and statistical comparison between measured and derived equations are documented in (Table 3\&4). The equations are observed to be

unique and not the same to formulas recorded in previous studies of other world populations. The results of comparison between measured and reconstructed stature from hand variables did not show any statistical significant difference, which implies that the derived regression models can effectively predict the stature of this study population.

Table 3: Multiple regression models for stature reconstruction from right and left-hand dimensions in the male and female sample.

\begin{tabular}{|c|c|c|c|}
\hline Males & Regression Equations & $\mathbf{\pm S E E}$ & $\mathbf{R}^{\mathbf{2}}$ \\
\hline Right Hand Dimensions & $\mathrm{SS}=(4.37 \times \mathrm{RHL})+(-0.85 \times \mathrm{RHB})+94.37$ & 4.22 & 0.571 \\
\hline Left Hand Dimensions & $\mathrm{SS}=(4.37 \times \mathrm{LHL})+(-0.75 \times \mathrm{LHB})+95.88$ & 4.22 & 0.56 \\
\hline Females & Regression Equations & $\mathbf{\pm S E E}$ & $\mathbf{R} 2$ \\
\hline Right Hand & $\mathrm{SS}=(3.98 \times \mathrm{RHL})+(1.81 \times \mathrm{RHB})+78.20$ & 4.69 & 0.51 \\
\hline Left Hand Dimensions & $\mathrm{SS}=(4.28 \times \mathrm{LHL})+(0.89 \times \mathrm{LHB})+80.75$ & 4.689 & 0.51 \\
\hline
\end{tabular}

Differences between measured stature and reconstructed stature**significant at $\mathrm{P}<0.01$.

Key

SS: Stretch Stature; RHL: Right Hand Lengt; LHL: Left Hand Length; RHB: Right Hand Breadth; LHB: Left Hand Breadth; SEE: Standard Error of Estimate

Table 4: Comparison of measured and reconstructed stature from multilinear regression models of right and left-hand dimensions in male and female.

\begin{tabular}{|c|c|c|c|c|}
\hline \multirow{2}{*}{$\begin{array}{c}\text { Direct Hand Param- } \\
\text { eters }\end{array}$} & \multicolumn{2}{|c|}{ Males } & \multicolumn{2}{c|}{ Females } \\
\cline { 2 - 5 } & Measured Stature (cm) & Reconstructed Stature (cm) & Measured Stature (cm) & Reconstructed Stature (cm) \\
\cline { 2 - 5 } & Mean $\pm S D$ & Mean $\pm S D$ & $164.38 \pm 6.62$ & Mean $\pm S D$ \\
\hline Right Hand & $176.36 \pm 8.13$ & $176.36 \pm 4.04$ & $164.38 \pm 6.62$ & $164.38 \pm 4.71$ \\
\hline Left Hand & $176.36 \pm 8.13$ & $176.36 \pm 4.72$ & & 0.86 \\
\hline p-value & & 0.88 & & $164.35 \pm 70$ \\
\hline
\end{tabular}

Differences between measured stature and reconstructed stature statistical significant at $\mathrm{P}<0.01$.

Key:

SD: Standard Deviation

P-value $<0.01=$ statistical significant difference in mean value of the measured and reconstructed stature 
(Figure 3-6) present the results of association between stretch stature and hand dimensions for the males and females, left and right hand respectively. The single linear regression equations were formulated for each hand dimension to predict stature. It was observed that hand length will predict stature more accurately than the hand breadth because hand length recorded higher values for coefficients of determination $\left(\mathrm{R}^{2}\right)$ than the hand breadth in both sexes. Therefore, it can be inferred that hand length is a better determinant and predictor of stature than hand breadth.

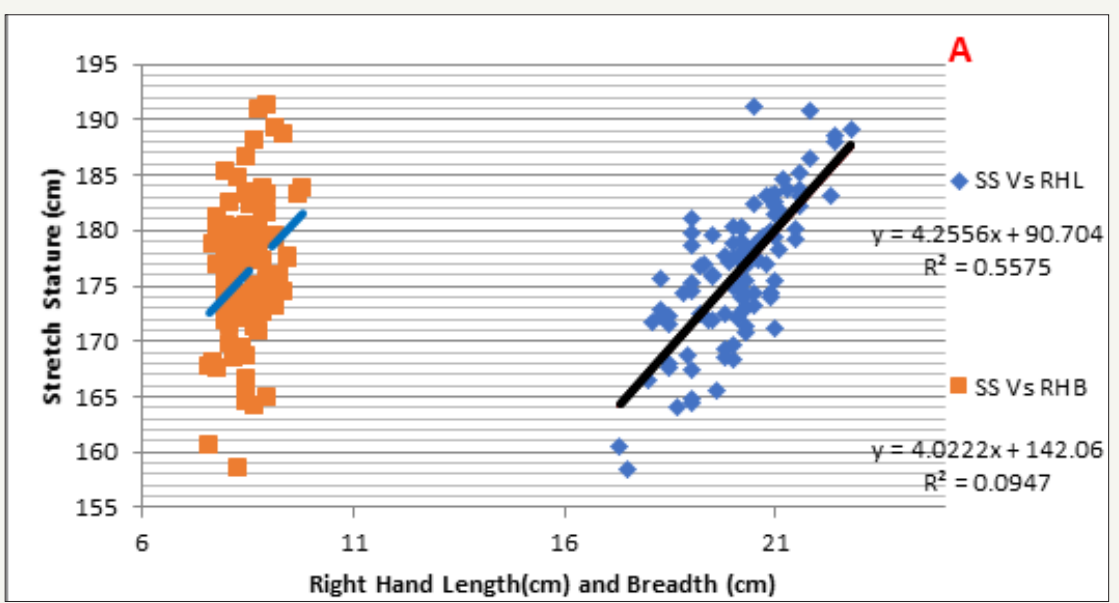

Figure 3: Linear scattered plots of stretch stature $(\mathrm{cm})$ Vs right Hand length (RHL) and Right-Hand breadth in the Males.

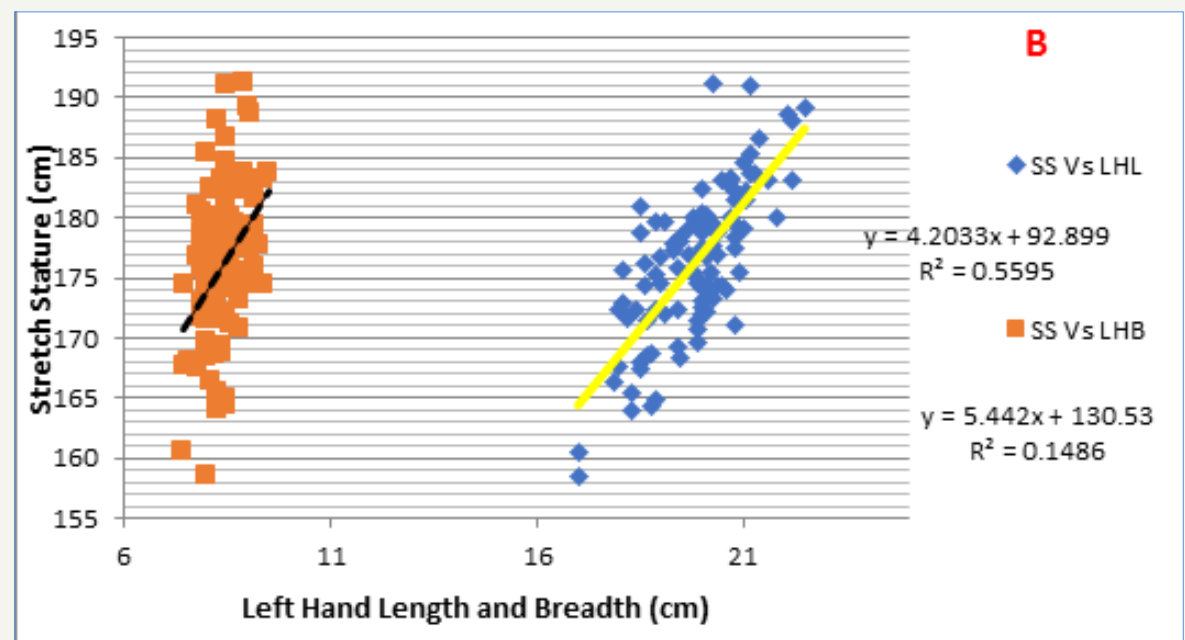

Figure 4: Linear scattered plots of stretch stature $(\mathrm{cm})$ Vs left Hand Length (LHL), and Left-Hand Breadth (LHB) in the Males.

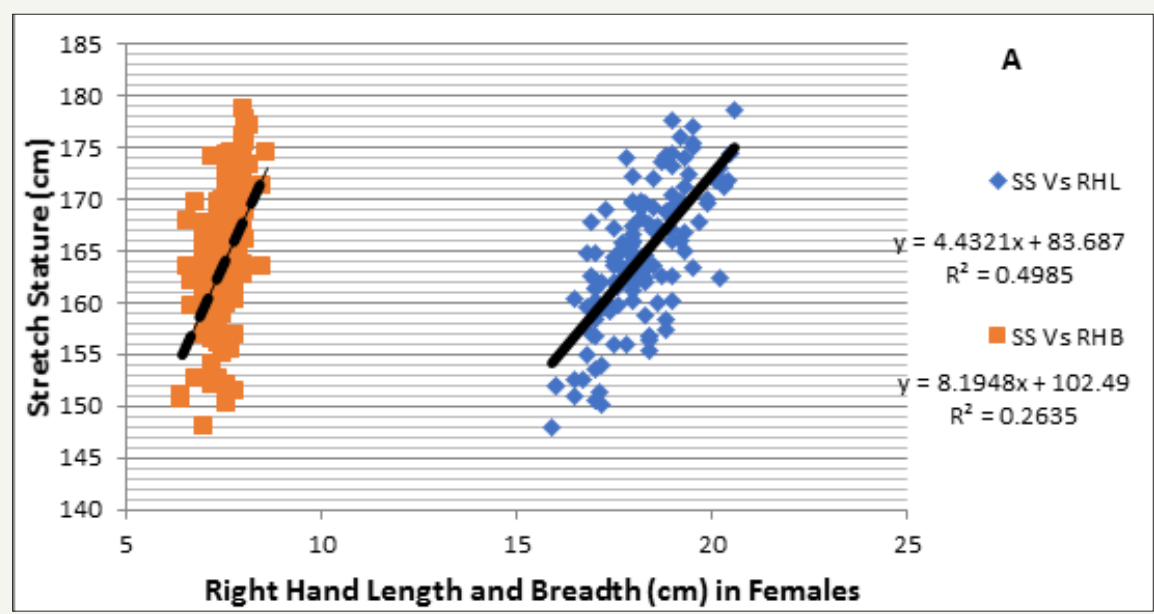

Figure 5: Linear scattered plots of stretch Stature $(\mathrm{cm})$ vs Right Hand length (RHL) and Right-Hand breadth (RHB) in the Females. 


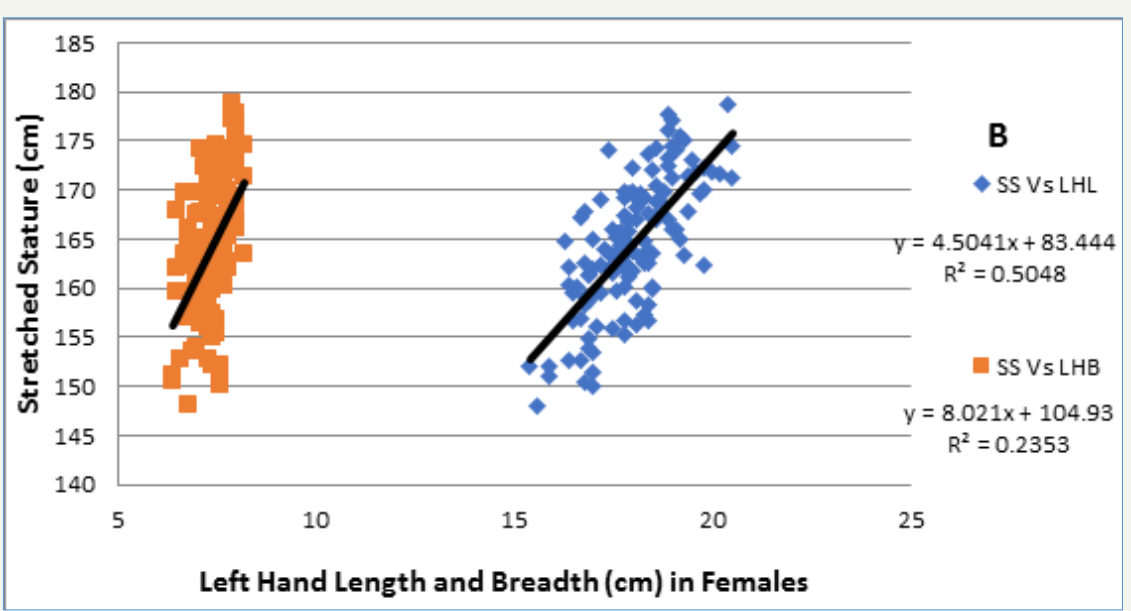

Figure 6: Linear scattered plots of stretch Stature $(\mathrm{cm})$ vs left Hand length (LHL) and left-Hand breadth (LHB) $(\mathrm{cm})$ in the Females.

\section{Discussion}

The stature of a person is genetically predetermined as an inherent characteristic, although nutritional and environmental influences play a role in the stature of an individual [3-4]. Stature estimation is one of the most widely used body parameters in forensic anthropology and will assist in establishing the biological profile of a person [13]. No two populations have the same average mean value for stature [14]. The present study recorded an average stature of $176.36 \pm 8.13 \mathrm{~cm}$ in the male and $164.38 \pm 6.62 \mathrm{~cm}$ in female (Table 1) with obvious significant differences $(\mathrm{P}<0.01)$ between the males and females. This is an indication that adult male Nigerians are taller than their female counterpart. Alongside the results of descriptive statistics is the results of independents sample test that depicts the level of significance $(\mathrm{P}<0.01)$ with regards to gender differences. The mean values showed statistical significant different between male and female with consistent higher values recorded in the males than the females.

Direct hand parameters measured when correlated with stature, gave a range of values of Pearson correlation coefficient $(r)$ as shown in (Table 2) and (Figure 3-6). The relationship between hand dimensions and stature ranges between 0.31 to 0.75 for the male and female with weakest value observed in male right hand breadth (RHB) while strongest correlation was seen with male right hand length (RHL). It was also observed that the weaker the correlation value the lower the strength of prediction meaning there is a high standard error of estimates S.E.E (Table 3 \&Figure 3-6). The results of Pearson correlation values ( $r$ ) of the present study for both left and right hands in both sex (Table 2) were stronger when compared with the values seen in the findings of Chandra et al. [11] that documented a weaker correlation coefficient of 0.598 for hand length (HL) and 0.460 for Hand breadth (HB) in Haryana males. But the results of Krishan and Sharma [7] observed correlation value in female to be $r=0.686$ and $r=0.677$ for the left and right-hand length and 0.403 and $r=0.503$ for the left and right handbreadth respectively.

The findings of Prateek et al. [20] on southern Indians recorded Pearson correlation coefficient with a range between 0.752 to
0.732 for the males and 0.701 to 0.691 for the females which were higher than the association between hand length and stature recorded in the present study. In tandem with the present study, the finding of Sharaf El Din et al. [21] showed a positive significant correlation in both the simple linear and multiple linear regression formulas employed in both sexes to reconstruct stature from hand dimensions, the values for the measured stature for the males and their female counterpart when compared with the predicted values showed no statistical significant difference.

The simple linear and multilinear regression models derived from hand dimensions of left and right hands in male and female showed varying level of predictions of stature as seen in the different values of standard error of estimates (S.E.E) in (Table 3). Differences in the S.E.E are indications that everybody parts in the human, estimate stature with different level of reliability and hand length is among the foremost parameters [22].

The values of the average stature from this study were also different from the findings of Akhlaghi et al. [2] on the Iranians which recorded that the males had an average value of $171.12 \mathrm{~cm}$ which varies from the values seen in the findings of Moorthy et al. [6] on Malaysian Malays which reported average stature of $168.70 \mathrm{~cm}$ in male and $156.30 \mathrm{~cm}$ in the female. Even the reports of Krishan et al. [13] and Krishan et al. [16] on North and south Indian Populations established different results for the stature in the males and females and the derived regression equations also differs. The outcome of Tang et al. [23] among the Southern Chinese and that of Sharaf El Din et al. [21] in an Egyptian population reported that the male values were consistently higher than the values recorded in the females, but the two-population showed variation in stature and regression formulas.

Pal et al. [24] documented that higher values in males Bangalee population than their females which conforms with the present data. But it is noteworthy that the various data gotten from different studies recorded contrasting regression formulas derived from hand parameters and the average stature gotten from the present study in both sexes. 
Thus, this study showed that the higher the S.E.E, the lower the chances of prediction while the lower the S.E.E value, the higher the reliability of stature reconstruction and this is in tandem with the findings of [24-30] on other climes.

\section{Conclusion}

The present study will provide a database on an adult Nigerian population for the prediction of stature from hand dimensions. This could lead to the development of a standard for such data on young adult Nigerians. The comparison made with the other studies on different world population could contribute to the understanding of the relative status of Nigerian population in the context of the anthropometric variations around the world. Hence, the regression formulas derived from hand variables, may be of help when reconstructing stature from dismembered body parts, but it is only peculiar to a Nigerian population.

\section{References}

1. Agnihotri AK, Agnihotri S, Jeebun N, Googoolye K (2008) Prediction of stature using hand dimensions. J Forensic Legitimate Med 15(8): 479482.

2. Akhlaghi M, Hajibeygi M, Behzad MB (2012) Estimation of stature from upper limb anthropometry in Iranian population. J Forensic and Legal Med 19(5): 280-284.

3. Nandi ME, Olabiyi OA, Ibeabuchi NM, Okubike EA, Iheaza EC (2018) Stature reconstruction from percutaneous anthropometry of long bones of upper extremity of Nigerians in the University of Lagos. Arab J Forensic Sci and Forensic Med 1(7): 869-880.

4. Anas IY, Esomonu UG, Zagga AD (2010) Prediction of stature of Hausa ethnic group using hand length and breadth. J Medical Tropics 12(1): 30-32.

5. Nandi ME, OkubikeEA, Obun CO, Onen ON (2017) Derivation of regression equations for stature estimation from digit lengths of Nigerian medical students in University of Lagos. Arab J Forensic Sciences and Forensic Med 1(6): 683-694

6. Moorthy N, Zulkifly NRB (2014) Regression analysis for stature determination from hand anthropometry of Malaysian Malays for forensic investigation. Sri Lanka J. Forensic Medicine, Sci \& LawDecember 5: 2-8.

7. Oria RS, Igiri AO, Egwu OA, Nandi ME (2016) Prediction of stature from hand length and breadth - anthropometric study on an adult Cross River State population. Annals of Bioanthropology 4(1): 12-16.

8. Chikhalkar BG, Mangaonkar AA, Nanandkar SD, Peddawad RG (2009) Original research paper Estimation of Stature from Measurements of Long Bones, Hand and Foot Dimensions. J Indian Academics Forensic Medical 32(4): 329.

9. Athawale M (1963) Estimation of height from lengths of forearm bones. A study of one hundred Maharashtrian male adults of ages between twenty-five and thirty years. American Journal of physical anthropology 21(2): 105-112.

10. Saxena S (1984) A study of correlations and estimation of stature from hand length, hand breadth and sole length. Anthropologischer Anzeiger 42 (4): 271-276

11. Chandra A, Chandna P, Deswal S, Mishra RK, Kumar R (2015) Stature prediction model based on hand anthropometry. Int'l J. Medical, Health, Biomedical, Bioengineering and Pharmaceutical Engineering 9(2): 1-7.
12. Hossain S, Begun JA, Banu LA, Rahman F, Akhter Z (2010) Prediction of stature from hand length and breadth-An Anthropometric study on Christian Gara tribal Bangladeshi females. Bangladesh J Anatomy 8(1): 21-27.

13. Krishan K, Sharma JC (2007) Estimation of stature from dimensions of hands and feet in a North Indian population. J Forensic and Legal Medicine 14: 327-332.

14. Chandna P, Deswal CR, Chandra A (2010) An anthropometric survey of industrial workers of the northern region of India. Int'l J Industrial and Systems Eng 6(1): 110-128.

15. Krishan K, Kanchan T, Sharma A (2012) Multiplication factor versus regression analysis in stature estimation from hand and foot dimensions. J Forensic Leg Med 19: 211-214.

16. Krishan K, Kanchan T, Asha N (2012) Estimation of stature from index and ring finger length in a north Indian adolescent population. J forensic and legal med 19: 285-290.

17. Nandi ME, Ibeabuchi NM, Olabiyi OA, Okubike EA, Iheaza EC (2018) Stature reconstruction from handprint dimensions in an adult Nigerian student population. Forensic Sci \& Add Res 2(5): 1-9.

18. Ishak NI, Hemy N, Franklin D (2012) Estimation of stature from hand and handprint dimensions in a Western Australian population. Forensic Sci. Int'l J 216(1-3): 1991-1997.

19. Okubike EA, Ibeabuchi NM, Olabiyi OA, Nandi ME (2018) Stature estimation from footprint dimensions in an adult Nigerian student population. J Forensic Sci Med 4(1): 7-17.

20. Prateek R, Nags KR, Yoganarasimha AK (2008) Estimation of stature from hand dimensions of north and south Indians. Legal Med 10(4): 185-189.

21. Khaled EA, Soheir AM, Maha AH, Eman AM (2011) Determination of sex from hand dimensions and index/ring finger length ratio in Upper Egyptians. Egyptian J Forensic Sci 1(2): 80-86.

22. Sharaf El Din AA, Elkholy MS, Yousef MI (2015) Prediction of stature based on upper limb measurements among Egyptian population. Eur J Forensic Sci 3(2): 233-238

23. Tang J, Chen R, Lai X (2012) Stature estimation from hand dimensions in a han population of Southern China. J Forensic Sci 57 (6): 1541-1544.

24. Pal A, De S, Sengupta P, Maity P, Dhara PC (2016) Estimation of stature from hand dimensions in Bengalee population, West Bengal, India. Egyptian J Forensic Sci 6(2): 90-98.

25. Jobby A, Naik L (2015) Estimation of stature from measurement of hands and feet in Kollam region. Journal of Research in Forensic Med and Toxicology 1(1): 14-15.

26. Sharma R, Sethi PD, Garg A, Dhattarwal SK, Chawla R (2016) Estimation of Stature from Length Thumb. Asian J. Med and Sci 4(2): 79-84.

27. Chandra A, Chandna P, Deswal S, Kumar R (2009) "Ergonomics in the office environment: a review," in Proceedings of Int'l Conference on Energy and Environment, Chandigarh, India.

28. Iscan MY (2012) Forensic anthropology of sex and body size. Forensic Sci Int'l J 147: 107-112.

29. Kachan T, Krishan K (2011) Anthropometry of hand in sex determination of dismembered remains -a review of literature. J Forensic and Legal Med 18(1): 14-17.

30. Kanchan T, Rastogi P (2009) Sex determination from hand dimensions of North and South Indians. J. Forensic Sci 54(3): 546-550. 
Creative Commons Attribution 4.0 International License

For possible submissions Click Here

Submit Article

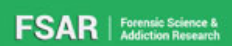

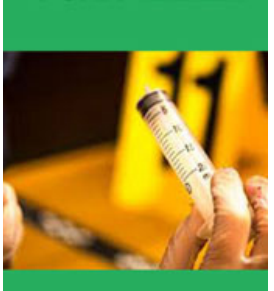

Forensic Science \& Addiction Research

\section{Benefits of Publishing with us}

- High-level peer review and editorial services

- Freely accessible online immediately upon publication

- Authors retain the copyright to their work

- Licensing it under a Creative Commons license

- Visibility through different online platforms 